\title{
Determination and Preconcentration of Copper(II) after Adsorption of Its Cupferron Complex onto Benzophenone
}

\author{
Taikjin Lee and Hee-Seon Choi ${ }^{*}$ \\ Department of Chemistry, The University of Suwon, P.O. Box 77, Stwon 445-743, Korea \\ Received Jamary 29, 2002
}

\begin{abstract}
A sensitive method for the determination of trace copper(II) after the preconcentration by adsorbing its cupferron complex onto microcrystalline benzophenone was developed. Several experimental conditions such as the $\mathrm{pH}$ of sample solution. concentration of cupferron, amount of benzophenone and stirring time were optimized. Trace copper(II) in $100 \mathrm{~mL}$ solution was chelated with $3.0 \times 10^{-3} \mathrm{M}$ cupferron at pH 5.0. After 0.20 $\mathrm{g}$ benzophenone was added, the solution was stirred for 40 mimutes to adsorb the complex quantitatively onto benzophenone. The benzophenone adsorbing Cu-cupferron complex was filtered and then Cu-cupferron complex was desorbed in $10 \mathrm{~mL}$ ethanol. Copper was determined by a flame atomic absorption spectrophotometry. The interfering effects of diverse concomitant ions were investigated. Fe(III) interfered seriously with, but the interference by $\mathrm{Fe}$ (III) was completely eliminated by adjusting the concentration of cupferron to $5.0 \times 10^{-3} \mathrm{M}$. The detection limit of this method was $8.6 \times 10^{-8} \mathrm{M}\left(5.5 \mathrm{ngmL}^{-1}\right)$. Recoveries of $97 \%$ and $96 \%$ were obtained for $\mathrm{Cu}(\mathrm{II})$ in a stream water and a brass sample, respectively. Based on the results from the experiment, this proposed technique could be applied to the determination of copper(II) in real samples.
\end{abstract}

Keywords : Copper, Adsorption, Benzophenone, Brass, Flame atomic absorption spectrophotometry.

\section{Introduction}

Liquid-liquid extraction has widely been used as one of techniques by which trace metal ions in aqueous solution could be separated and concentrated. ${ }^{1}$ However, liquidliquid extraction has some limitations that are time-consuming, tedious, and usually involve harmful solvents. Some metal complexes that slightly dissolve in liquid solvent and are stable in solution at high temparature could be concentrated and extracted more efficiently, rapidly and quantitatively by solid-liquid separation using microcrystalline naphthalene or benzophenone. ${ }^{2,3}$ But this method suffers from the volatility of the fused organic material and decomposition of $\mathrm{Cu}$-cupferron complex caused by a high temperature of $70-90^{\circ} \mathrm{C}$. In order to overcome this difficulty, a modified technique based on the adsorption of metal complex at room temperature onto microcrystalline organic substances was used. ${ }^{49}$

UV-visible spectrophotometry has usually been used to determine the analytes after solid-liquid separation. ${ }^{10-12}$ Although UV-visible spectrometric techniques are simple, convenient and more economical than flame AAS, they also have limitation that the spectral interference due to overlapping of the maximum absorption wavelengths may occur when various metal ions are contained in real samples.

Cupferron (ammonium nitrosophenylhydroxylamine) combines with several metal ions such as copper, iron and so forth to form colored metal complexes that are not dissolved in aqueous solution. ${ }^{13}$ This chelating agent has been used to determine several metal ions by UV-visible spectrophotometry and also by adsorptive stripping voltammetric analysis using good adsorptive characteristics of cupferron complex. ${ }^{1+16}$

For the preconcentration and separation of copper(II) ion, various solid adsorbents such Amberlite XAD-4 resin, ${ }^{1 ?}$ silica gel, ${ }^{18}$ activated carbon, ${ }^{19}$ and thiol cotton ${ }^{20}$ have been used. These adsorbents have good preconcentration yields and high recovery yields for some copper(II) complexes. However, these techniques are troublesome and time-consuming because of slow sorption and desorption process. It was ezpected that $\mathrm{Cu}(\mathrm{II})$-cupferron complex would be adsorbed on microcrystalline benzophenone well and rapidly, because of a very similar polarity.

The determination of trace amounts of copper has received considerable attention in the battle against environmental pollution. In the determination of copper, various methods, including inductively coupled plasma-mass spectrometry, ${ }^{21}$ ion chromatography, ${ }^{22}$ anodic stripping analysis, ${ }^{23}$ and graphite furnace atomic absorption spectrophotometry ${ }^{2+}$ have been used. Many of these methods are either time-consuming or require complicated and expensive instruments.

Therefore, the method that could determine trace amount of copper rapidly and conveniently by using preconcentration technique onto benzophenone was researched. In this study, the determination of copper(II) was performed after separation and adsorption of its cupferron complex onto benzophenone.

\section{Experimental Section}

Reagents and Solutions. All chemicals used in this experiment such as $\mathrm{Cu}\left(\mathrm{NO}_{3}\right)_{2} \cdot 7 \mathrm{H}_{2} \mathrm{O}$ (Aldrich Co.) were of analytical grade and guaranteed grade reagents. Copper standard solution was made with $10^{-2} \mathrm{M}$ stock solution 
prepared from copper(II) nitrate by a dilution. Because cupferron (Wako Co.) is slowly decomposed by heat, $0.10 \mathrm{M}$ cupferron solution was made whenever needed. Benzophenone (Aldrich $\mathrm{Co}$.) ground in an agitate mortar was used without further purification prior to use. The deionized water by a Barnstead catridge deionization system was used throughout all experimental procedures.

Instrumentation. GBC model 903 flame atomic absorption spectrophotometer was used in following conditions: 10 cm 1-slot burner, copper hollow cathode lamp of Photron Dty. Ltd., wavelength: $324.7 \mathrm{~nm}$, air-acetylene flame, burner height: $15 \mathrm{~mm}$, lamp current: $3.0 \mathrm{~mA}$. Copper in real samples was determined directly with a HP 4500 ICP-MS spectrometer. A Bantex model $300 \mathrm{~A}$ digital $\mathrm{pH}$ meter with a combined glass and calomel electrode was used to adjust the $\mathrm{pHs}$ of all sample solutions.

General Procedures. A $100 \mathrm{~mL}$ copper(II) sample solution was taken into a $250 \mathrm{~mL}$ Erlenmeyer flask, and 3.0 $\mathrm{mL}$ of $0.10 \mathrm{M}$ cupferron was added. The $\mathrm{pH}$ was adjusted to 5.0 using $0.1 \mathrm{M} \mathrm{HNO}_{3}$ and $0.20 \mathrm{~g}$ benzophenone was added as a solid solvent. This solution was stirred for 40 minutes to adsorb quantitatively Cu-cupferron complex onto benzophenone. After filtered with fritted glass filter (1-G-4), this microcrystalline benzophenone was washed with deionized water and dissolved in $10 \mathrm{~mL}$ volumetric flask with ethyl alcohol. The absorbance of copper was measured on the basis of $\mathrm{Cu}$-free blank solution at $324.7 \mathrm{~nm}$ with flame atomic absorption spectrophotometer. A calibration curve was prepared in the range of $5.0 \times 10^{-7} \mathrm{M}-1.0 \times 10^{-5} \mathrm{M}$ of copper(II) by the above procedure. A brass sample was prepared as follows. To remove the impurities on the surface of the brass sample, it was washed with acetone and deionized water. A $0.1000 \mathrm{~g}$ brass sample was weighed and transferred to a $250 \mathrm{~mL}$ Erlenmeyer flask, added by $10 \mathrm{~mL}$ of $6 \mathrm{M} \mathrm{HNO}$, heated in fume hood until it dissolved completely, and cooled down to the room temperature. This brass solution was transferred to $1000 \mathrm{~mL}$ volumetric flask and diluted by filling to the mark. A $1.0 \mathrm{~mL}$ aliquot of the solution was diluted further to a $1000 \mathrm{~mL}$ in a volumetric flask with deionized water and used as a real sample. A 100 $\mathrm{mL}$ aliquot of stream water sample was taken after the suspended matters or particles were filtered out with glass filter (1-G-4).

\section{Results and Discussion}

Concentration of Cupferron. To extract metal complex quantitatively, more chelating agent must be added to the sample solution than its stoichiometric ratio. The extraction efficiency in $3.0 \times 10^{-6} \mathrm{M}$ copper(II) solution was investigated by adjusting concentrations of cupferron from $3.0 \times$ $10^{-4} \mathrm{M}$ to $5.0 \times 10^{-3} \mathrm{M}$. Figure 1 shows that the absorbance was practically constant when the concentration of cupferron was above $2.0 \times 10^{-3} \mathrm{M}$. In this experiment, $3.0 \times 10^{-3}$ $\mathrm{M}$ cupferron solution was used.

pH. The $\mathrm{pH}$ level is an important factor according to which $\mathrm{Cu}(\mathrm{II})$ combine with cupferron to be a stable complex.

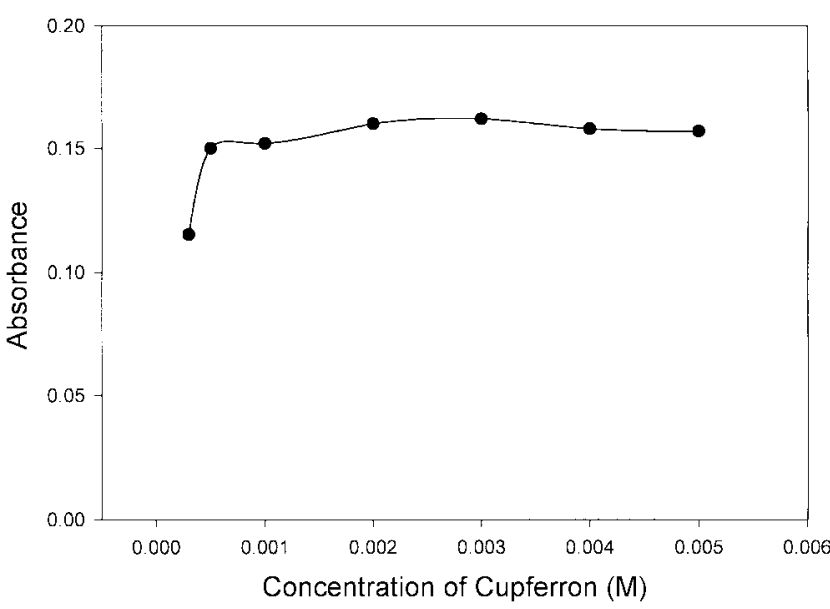

Figure 1. Extraction efficiency of $\mathrm{Cu}(\mathrm{II})\left(3.0 \times 10^{-6} \mathrm{M}\right)$ according to the concentration of cupferron at $\mathrm{pH} 5.0$.

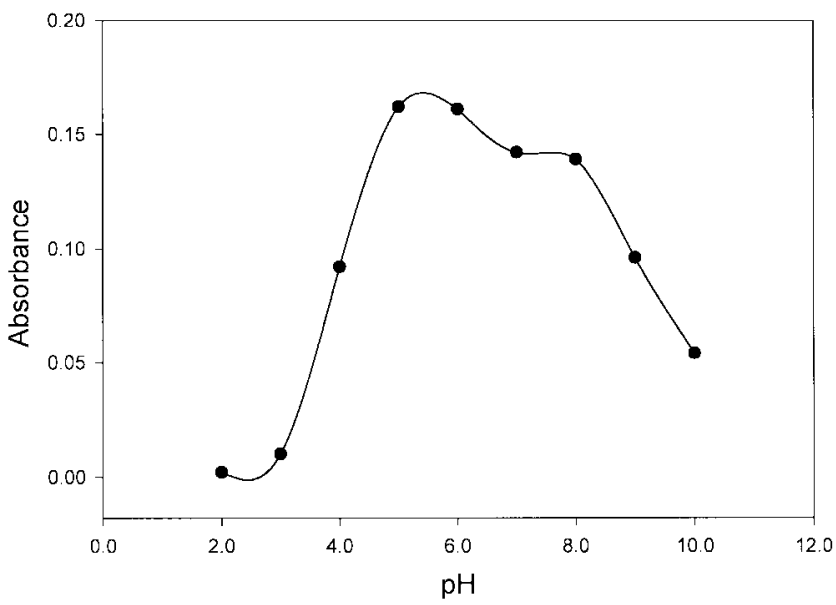

Figure 2. Effect of $\mathrm{pH}$ on the separation of the Cu(II)-cupferron chelate $)[\mathrm{Cu}(\mathrm{II})]=\left(3.0 \times 10^{-6} \mathrm{M}\right)$.

The $\mathrm{pH}$ of the $100 \mathrm{~mL}$ solution containing $3.0 \times 10^{-6} \mathrm{M}$ copper(II) and $3.0 \times 10^{-3} \mathrm{M}$ cupferron was carefully adjusted from 2.0 to 10.0 with $0.1 \mathrm{M} \mathrm{HNO}_{3}$ or $0.1 \mathrm{M} \mathrm{NaOH}$ to form the Cu-cupferron complex quantitatively. The $0.20 \mathrm{~g}$ benzophenone was added to this solution and the effect of $\mathrm{pH}$ on the extraction of $\mathrm{Cu}$-cupferron complex was investigated. As shown in Figure 2, the absorbance of extracted copper(II) depended on the $\mathrm{pH}$ with the maximum absorbance obtained in the range of $\mathrm{pH} 5.0-6.0$. Below $\mathrm{pH} 5.0$, it seems that the Cu-cupferron complex was not formed quantitatively on account of protonationing of the chelating agent. At higher $\mathrm{pH}$, it is likely that $\mathrm{Cu}$-cupferron complex was not formed quantitatively because it competed with copper hydroxide precipitation. Hence, $\mathrm{pH} 5.0$ was chosen in this experiment.

Amount of Benzophenone. The adsorption efficiency of Cu-cupferron complex onto benzophenone was investigated by varying the amount of benzophenone as the microcrystalline adsorbent from 0.05 to $0.30 \mathrm{~g}$ (Figure 3). The complex was quantitatively extracted on the addition of $0.05-0.20 \mathrm{~g}$ benzophenone. Below $0.10 \mathrm{~g}$, however, the reproducibility of the extraction with adsorbing was diminished. Above 


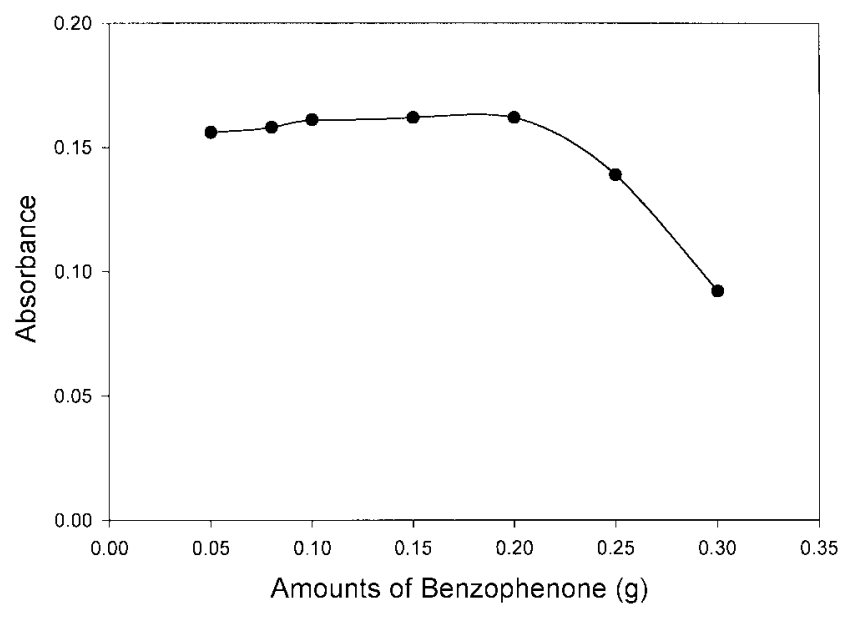

Figure 3. Variation of the absorbance of C.U(II) $\left(3.0 \times 10^{-6} \mathrm{M}\right)$ in various amounts of benzophenone at $\mathrm{pH} 5.0$.

$0.25 \mathrm{~g}$, it was difficult to use because the capillary tube of the flame AAS was often clogged. Thus, $0.20 \mathrm{~g}$ of benzophenone was used as the suitable amount. The stirring time affects the distribution equilibrium in which the nonionic complex adsorbs onto the microcrystalline benzophenone. To investigate the effect of stirring time on the adsorption of Cu-cupferron complex onto benzophenone in sample solution, the stirring was conducted from 10 minutes to 120 minutes. The extraction efficiency was good when the stirring time was 30 to 45 minutes. So, the sample solution was stirred for 40 minutes.

Interfering Effects. The possible interfering effects of concomitant ions on the determination of copper were investigated under optimum conditions given above. Various metal ions and salts were used for investigation of their interference effects on $3.0 \times 10^{-6} \mathrm{M}\left(0.19 \mu \mathrm{gmL}^{-1}\right)$ copper solution, because it was assumed that they prevent the $\mathrm{Cu}$ cupferron complex from forming. The results of interference studies are summarized in Table 1. Fe(III) even at more than $1.0 \mu \mathrm{gmL}^{-1}$ caused to serious interference. It is assumed that such interfering effect was caused by the complexation of Fe(III) with cupferton prior to copper(II). However, the interference by $\mathrm{Fe}(\mathrm{III})$ could be overcome sufficiently by adjusting the concentration of cupferron to $5.0 \times 10^{-3} \mathrm{M}$.

Applications to Real Samples. A calibration curve was constructed at optimum conditions according to general procedure described above. The linear range of $\mathrm{Cu}(\mathrm{II})$ was $5.0 \times 10^{-7} \mathrm{M}-1.0 \times 10^{-5} \mathrm{M}$. The correlation coefficient $\left(\mathrm{R}^{2}\right)$ was 0.9993 , showing a good linearity of calibration curve.
Table 1. Tolerance limit ${ }^{a}$ for diverse metal ions and salts in $3.0 \times$ $10^{-6} \mathrm{M}(0.19 \mu \mathrm{g} / \mathrm{mL}) \mathrm{Cu}(\mathrm{II})$ solution containing $3.0 \times 10^{-3} \mathrm{M}$ cupferron

\begin{tabular}{cccc}
\hline Ion/salts & $\mu \mathrm{g} / \mathrm{mL}$ & Ionisalts & $\mu \mathrm{g} / \mathrm{mL}$ \\
\hline $\mathrm{KSCN}$ & 30 & $\mathrm{Fe}(\mathrm{III})$ & 1.0 \\
$\mathrm{Na}_{2} \mathrm{C}_{2} \mathrm{O}_{4}$ & 30 & $\mathrm{~Pb}(\mathrm{II})$ & 100 \\
$\mathrm{NaClO}_{3}$ & 100 & $\mathrm{CdII})$ & 50 \\
$\mathrm{Na}_{3} \mathrm{Citrate}$ & 10 & $\mathrm{Sn}(\mathrm{II})$ & 30 \\
$\mathrm{Ni}(\mathrm{II})$ & 30 & $\mathrm{Co}(\mathrm{II})$ & 50 \\
$\mathrm{Zn}(\mathrm{II})$ & 30 & & \\
\hline
\end{tabular}

"Tolerance limit is the maximum concentration in which there is less than $3 \%$ effect on absorbance.

The detection limit is defined as the sample concentration giving a signal equal to the blank average signal plus three times the standard deviation of blanks. ${ }^{25}$ The detection limit obtained from the signals of twenty-three blank solutions and the slope of calibration curve, was $8.6 \times 10^{-8} \mathrm{M}(5.5$ $\left.n g m L^{-1}\right)$.

$\mathrm{Cu}(\mathrm{II})$ in Suwon stream water and diluted brass sample were determined by this proposed method and the results are shown in Table 2 . The recovery yields in the real samples spiked with $2.00 \times 10^{-6} \mathrm{M} \mathrm{Cu}(\mathrm{II})$ were determined, and found to be more than $95 \%$. In this determination, the relative standard deviations were less than $4.0 \%$. Cu(II) in real samples were also deternined by ICP-MS spectrometry. No difference between results from the proposed method and the ICP-MS method had been established at $95 \%$ confidence level. Therefore, this proposed technique could be applied to the determination of copper(II) in real samples.

\section{References}

1. Lo, T. C.: Baird, M. H. I.: Hanson, C. Handbook of Solvent Extraction; John Wiley \& Sons: New York, 1983; p 629.

2. Satake. M. Anal. Chin. Acta 1977, 92. 423.

3. Mehra. M. C.; Puri. B. K.; Iwasaka. K. Analyst 1985. 110, 791.

4. Bums, D. T.: Chimpalee, D. Anal Chim .4cta 1992, 256, 87.

5. Bums, D. T.: Tunkananuruk, N. Anal Chim Acta 1989, 219, 323.

6. Nagahiro, T.: Wang, G. F.; Satake, M. Microchem. J. 1985, 52, 247.

7. Puri. B. K.; Balani. S. Talanta 1995, 42.337.

8. Oh, H.; Choi, H. Anal. Sci, 2000, 16, 183.

9. Taher, M. A. Anal Chim. Acta 2000, 408, 153.

10. Kumar, A. Anal Sci. 1995, 11, 281.

11. Du, X.: Hou, J.; Zhao, S.; Kang, J.; Gao, J. Analyst 1994, 119 , 1891.

12. Kojima. T.; Shigetomi, Y. Anal. Chim. Acta 1989. 219, 171.

Table 2. Analytical data of Cu(II) in real samples

\begin{tabular}{ccccc}
\hline \multirow{2}{*}{ Samples } & Spiked $(\mathrm{M})$ & \multicolumn{2}{c}{ Measured $(\mathrm{M})^{\natural}$} & \multirow{2}{*}{ Recovery $(\%)$} \\
\cline { 3 - 4 } & & This techrique & ICP-MS & \\
Stream water & 0.00 & $9.1( \pm 0.3) \times 10^{-7}$ & $8.9( \pm 0.6) \times 10^{-7}$ & 97 \\
(Suwon) & $2.00 \times 10^{-6}$ & $2.85( \pm 0.05) \times 10^{-6}$ & & \\
Diluted brass sample & 0.00 & $1.05( \pm 0.04) \times 10^{-6}$ & $1.08( \pm 0.08) \times 10^{-6}$ & 96 \\
& $2.00 \times 10^{-6}$ & $2.97( \pm 0.04) \times 10^{-6}$ & & 96 \\
\hline
\end{tabular}

"The mean values were obtained from 7 samples in this technique and 5 samples in ICP-MS technique. 
13. Welcher, F. J. Standard Methods of Chemical Analysis, 6th ed.; D. Van Nostrand: Princetorn. 1963; p 116.

14. Wang. J.; Lu. J; Wang. J.; Tian. B. Electroatalisis 1997, 9. 1247.

15. Sander, S. Fresenus J. And. Chem. 1999, 365, 435.

16. Satiadji. R.; Wang. J.; Santana-Rios, G. Talanta 1993, 40,845.

17. Uzum, A.; Soylak, M.; Elci, L. Talanta 2001. 54. 197.

18. Mahmoud. M. E.; Osman, M. M.; Amer. M. E. Anal Chim. Acta $2000,415,33$

19. Soylak, M.; Elci, L.; Dogan, M. Anal, Leth. 2000, 33, 513.
20. Quig, Y. M.; Quin. L. G. Talanta 1983. 30. 265.

21. Kato, T.; Nakamura, S.; Mirita, M. Anal. Sci. 1990, 6. 623.

22. Ohawa, S.; Yamazaki, K.; Ishikawa. T. Bunsekikagaku 1998, 47 , 861.

23. Staden, J. F.; Matoetoe, M. C. Anal Chim. Acta 2000, 411, 201.

24. Cundeva, K.; Statilov, T. Anal Lett. 1997, 301,833.

25. Skoog. D. A.; Holler. F. J.; Nieman. T. A. Principles of Instrimental Analysis. 5th ed.; Saunders College Publishing: 1998; $\mathrm{p}$ 13. 